\title{
New Methods in the Diagnosis of Prosthetic Joint Infection
}

\author{
S. Karbysheva, N. Renz, K. Yermak, S. Cabric, A. Trampuz \\ Center for Septic Surgery, Charité - University Medicine Berlin, Berlin, Germany
}

\begin{abstract}
A timely and accurate diagnosis of periprosthetic joint infection (PJI) is crucial to plan adequate treatment. Purpose of the study. To evaluate the performance of new diagnostic tests for the diagnosis of PJI. Material and Methods. The performance of novel biomarkers in synovial fluid (i.e. D-lactate and alfa-defensin), molecular test (i.e. PCR of synovial fluid and sonication fluid), new methods to dislodge biofilm from implant surface (i.e. MicroDTTect) and sonication of explanted prosthesis were investigated in patients with PJI and aseptic loosening of the prosthesis. Results. D-lactate showed better sensitivity for the diagnosis of PJI compared to leukocyte count (86\% and $80 \%$, respectively). The optimal D-lactate cut-off value was calculated at $1.26 \mathrm{mmol} / \mathrm{l}$. The ADLF test showed sensitivity of $84 \%, 67 \%$ and to $54 \%$ depending on classification criteria used for the diagnosis of PJI (Musculoskeletal Infection Society (MSIS), The Infectious Diseases Society of America (IDSA) and proposed European Bone and Joint Infection Society (EBJIS) criteria, respectively). Using the proposed EBJIS definition criteria, the sensitivity of the leukocyte count was significantly higher than that of the ADLF test ( $86 \%$ compared with $54 \% ; p<0,001)$, particularly in chronic PJI (81\% compared with $44 \%$, respectively; $p<0,001)$. The sensitivity of synovial fluid PCR was $60 \%$ and herewith comparable with synovial fluid culture $(52 \%, p=0,239)$. The sensitivity and specificity of sonication fluid culture were $58 \%$ and $100 \%$, which was comparable to sonication fluid PCR $51 \%$ and $94 \%$, respectively. DTT-based method showed low sensitivity for diagnosis of PJI (40\%) compared to sonication $(80 \%, p<0,01)$. Conclusion. Synovial fluid D-lactate demonstrated good analytical performance and diagnostic value for the diagnosis of PJI. In particular, the high sensitivity for diagnosing infection and rapid availability of the test result make synovial fluid D-lactate suitable as screening test, whereas ADLF had limited sensitivity (54\%) but high specificity (>95\%) and it should therefore not be used for screening, but rather as a confirmatory test for PJI. Multiplex PCR of synovial fluid and sonication fluid has similar sensitivity and specificity compared to synovial fluid culture, having the advantage of rapid availability of results (within 5 hours) and fully automated process. With further improvement of its performance and inclusion of additional primers, multiplex PCR may complement conventional cultures, especially for rapid and accurate diagnosis of low-grade PJI. Culture of samples obtained by sonication of prostheses showed better sensitivity for the microbiologic diagnosis of prosthetic hip and knee infection compared to chemical based dislodgement such as MicroDTTect.
\end{abstract}

Keywords: diagnosis of periprosthetic joint infection, biofilms, synovial fluid, novel diagnostic tests.

doi: 10.21823/2311-2905-2019-25-4-56-63

\section{Новые методы диагностики перипротезной инфекции}

\author{
С. Карбышева, Н. Ренц, К. Ермак, С. Кабрик, А. Трампуш
}

Центр костно-мышечной хирургии Шарите - Университетский медицинский комплекс Берлина, Берлин, Германия

\section{Реферат}

Актуальность. Своевременная и точная диагностика перипротезной инфекции суставов (ППИ) имеет решающее значение для планирования соответствующей тактики лечения. Цель исследования оценить эффективность новых диагностических тестов для диагностики перипротезной инфекции суставов. Материал и методы. Эффективность новых биомаркеров в синовиальной жидкости (D-лактат

Dd Cite as: Karbysheva S., Renz N., Yermak K., Cabric S., Trampuz A. New Methods in the Diagnosis of Prosthetic Joint Infection. Travmatologiya $i$ ortopediya Rossii [Traumatology and Orthopedics of Russia]. 2019;25(4):56-63. doi: 10.21823/2311-2905-2019-25-4-56-63.

$\triangle$ Svetlana Karbysheva; e-mail: svetlana.karbysheva@charite.de

Received: 16.08.2019. Accepted for publication: 30.09.2019. 
и альфа-дефенсин), ПЦР синовиальной жидкости и соникационной жидкости, новые методы разрушения бактериальных биопленок на поверхности имплантата таких как MicroDTTect и ультразвуковая обработка извлеченных имплантатов были исследованы у пациентов с ППИ и асептическим расшатыванием эндопротеза. Результаты. D-лактат синовиальной жидкости показал более высокую чувствительность для диагностики ППИ в сравнении с определением количества лейкоцитов в синовиальной жидкости (86\% и 80\%, соответственно). Пороговая концентрация D-лактата составила 1,26 ммоль/л. Чувствительность альфадефенсина составила 84\%, 67\% и 54\%, в зависимости от диагностических критериев ППИ (Musculoskeletal Infection Society (MSIS), The Infectious Diseases Society of America (IDSA) и предложенные критерии European Bone and Joint Infection Society (EBJIS), соответственно). Однако применяя критерии постановки диагноза EBJIS, чувствительность определения лейкоцитов была значительно выше, в сравнении с альфа-дефензином (86\% и 54\%, $p<0,001)$, особенно при хронической ППИ (81\% и 44\% соответственно; $p<0,001)$. Чувствительность мультиплексной ПЦР синовиальной жидкости составила $60 \%$ и при этом была сопоставима с культуральным исследованием синовиальной жидкости $(52 \%, p=0,239)$. Чувствительность и специфичность культурального исследования ультразвуковой жидкости составили 58\% и 100\% и были сопоставимы с ПЦР исследованием соникационной жидкости - 51\% и 94\% соответственно. Метод разрушения биопленок на поверхности имплантатов на основе дитиотреитиола (DTT) показал низкую чувствительность для диагностики ППИ (40\%) по сравнению с соникацией $(p<0,01)$. Заключение. D-лактат синовиальной жидкости продемонстрировал хорошие аналитические характеристики и диагностическую значимость для диагностики ППИ. В частности, высокая чувствительность и быстрота получения результата делают целесообзазным использовать D-лактат в качестве скринингового теста. Альфа-дефенсин обладает ограниченной чувствительностью (54\%), но высокой специфичностью (>95\%), поэтому его следует рассматривать скорее как подтверждающий тест. Мультиплексная ПЦР синовиальной и соникационной жидкости имеет сходную чувствительность и специфичность по сравнению с культуральным исследованием. Преимущество использования основано на более быстром получении результата исследования и полной автоматизации процесса. При дальнейшем улучшении диагностических характеристик, например включении дополнительных праймеров, мультиплексная ПЦР может дополнять рутинное микробиологическое исследование, особенно в случаях хронической ППИ. Микробиологическое исследование соникационной жидкости извлеченных имплантатов, показало более высокую чувствительность по сравнению с тестом MicroDTTect.

Ключевые слова: диагностика перипротезной инфекции, новые методы диагностики.

\section{Background}

Infections of prosthetic joints represent a serious complication, which is associated with high morbidity, prolonged treatment, and considerable health-care expenses [1, 2]. A timely and accurate diagnosis of infection is crucial to plan adequate treatment. Currently used preoperative diagnostic tests of synovial fluid lack both, high sensitivity and high specificity for infection $[3,4,5]$. Synovial fluid culture requires time and has limited sensitivity and specificity in particular in chronic, low-grade PJI.

The synovial fluid leukocyte count and differential (i.e. percentage of granulocytes) has high sensitivity, but may be increased without infection in case of underlying rheumatic joint disease, dislocations, periprosthetic fracture or within the first 6 weeks after surgery due to physiologic inflammatory healing process [6, 7]. Novel biomarkers in synovial fluid (i.e. D-lactate and alfa-defensin) and molecular test (i.e. PCR) may improve diagnosis of PJI $[8,9,10]$.

A major problem of intraoperative microbiological diagnosis of prosthetic joint infection (PII) is that biofilm-embedded bacteria are aggregated each other and attach on the surface of the implant, and therefore, they are difficult to detect without previous dislodgment and dispersion of biofilms [11, 12]. False negative PJI cases range from $7 \%$ to $20 \%$ using periprosthetic tissue cultures [13]. To improve biofilm removal from implant surface, different dislodgement approaches such as mechanical (sonication) or chemical (MicroDTTect) dislodgement were investigated.

\section{Material and Methods}

\section{Preoperative diagnostic tests}

To evaluate the performance of D-lactate, as a bacterial specific marker for the diagnosis of PJI, patients aged $\geq 18$ years diagnosed with prosthetic joint infections were prospectively included. Patients with aseptic pathology prosthetic joint (i.e. aseptic failure), in whom diagnostic aspiration was performed in the same aforementioned period, were included as a control group. Painful joints were aspirated as part of the routine diagnostic procedure in the emergency room, outpatient clinic or before incision of the joint capsule in the operating theatre. Synovial fluid D-lactate, leukocyte count and granulocyte percentage were determined. The receiver operating characteristic (ROC) analysis was performed to assess the diagnostic performance of D-lactate, leukocyte count and percentage of granulocytes.

To assess the efficacy of alfa-defensin (Alpha Defensin Lateral Flow Test - ADLF) for the diagnosis of PJI, patients in whom aspiration of a prosthetic hip or knee joint was performed before revision 
arthroplasty were prospectively included. In addition to standard diagnostic tests, the ADLF test was performed in synovial fluid. Patients were classified as having PJI or aseptic failure according to the definition criteria of the Musculoskeletal Infection Society (MSIS), the Infectious Diseases Society of America (IDSA), and the proposed criteria of the European Bone and Joint Infection Society (EBJIS). The performance of the ADLF test and the leukocyte count was compared using the McNemar $\chi^{2}$-square test.

For the evaluation of molecular method in the diagnosis of infection, patients in whom aspiration of the prosthetic hip or knee joint was performed before revision arthroplasty were prospectively included in the study. Synovial fluid obtained by aspiration of prosthetic hip or knee joints was analyzed by conventional diagnostic methods and by multiplex PCR. A multiplex PCR device (Unyvero, Curetis, Holzgerlingen, Germany) was used, allowing a semiquantitative DNA determination by eight multiplex $\mathrm{PCR}$ reactions in parallel.

\section{Intraoperative diagnostic tests}

To evaluate sonication method for the microbiologic diagnosis of PJI, we performed a prospective trial comparing culture of samples obtained by sonication $\left(40 \mathrm{kHz}, 0.1 \mathrm{~W} / \mathrm{cm}^{2}\right.$, BactoSonic, Bandelin electronic, Berlin, Germany) of explanted hip and knee prostheses with conventional culture of periprosthetic tissue among patients undergoing hip or knee revision or resection arthroplasty. For the PCR assessment, explanted joint prostheses were investigated by sonication and the resulting sonication fluid was analyzed by culture and multiplex PCR.

The performance of chemical dislodgement for the diagnosis of PJI was assessed on consecutive two groups of the patients with explanted knee and hip prosthesis due to PJI or aseptic failure (AF). The explanted prostheses were first investigated by using sonication, followed in the second group by using DTT-based (MicroDTTect, 4i for infection, Monza, Italy). For all patients of both groups synovial fluid leukocyte count, histopathology and culture of periprosthetic tissue samples were investigated.

\section{Results}

\section{Preoperative diagnostic tests}

\subsection{D-lactate}

Synovial fluid was analyzed from 148 prosthetic joints including 103 (70\%) cases with knee, 43 (29\%) with hip and $2(1 \%)$ - with shoulder prosthesis. Fortyfour patients (30\%) were diagnosed with PJI and 104 (70\%) with aseptic prosthetic failure. The majority of patients $(n=102,69 \%)$ underwent revision surgery, 62 of them with aseptic failures and 40 with PJI. The optimal D-lactate cut-off value was calculated at $1.26 \mathrm{mmol} / \mathrm{l}$. The sensitivity and specificity of the D-lactate test were $86 \%$ and $82 \%$, respectively. The synovial fluid leukocyte count showed a sensitivity of $80 \%$. However, in 12 patients the absolute or relative leukocyte count was elevated due to aseptic conditions, including rheumatologic joint disease $(n=3)$, recurrent dislocation $(n=2)$, early postoperative status $(n=2)$, trauma $(n=2)$, crystal arthropathy $(n=1)$, periprosthetic fracture $(n=1)$, and metallosis with crystals $(n=1)$ (Fig. 1$)$.

No significant differences were observed between any pairwise comparisons of AUCs between investigated synovial fluid biomarkers (AUCD-lactate vs AUC WBC $p=0.8$ ) (Fig. 2).
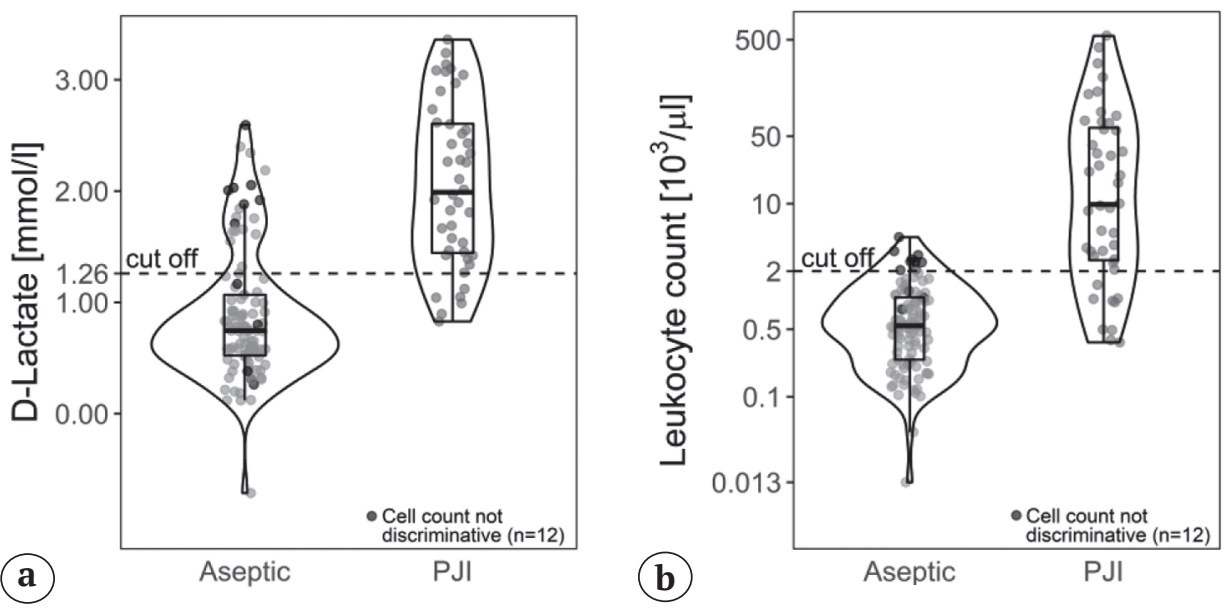

Fig. 1. Distribution of D-lactate (a) and leukocyte count (b) in aseptic failures and PJI. Twelve cases with underlying inflammatory conditions and elevated leukocyte count or/and percentage of granulocytes above the threshold are presented with dark grey dots 


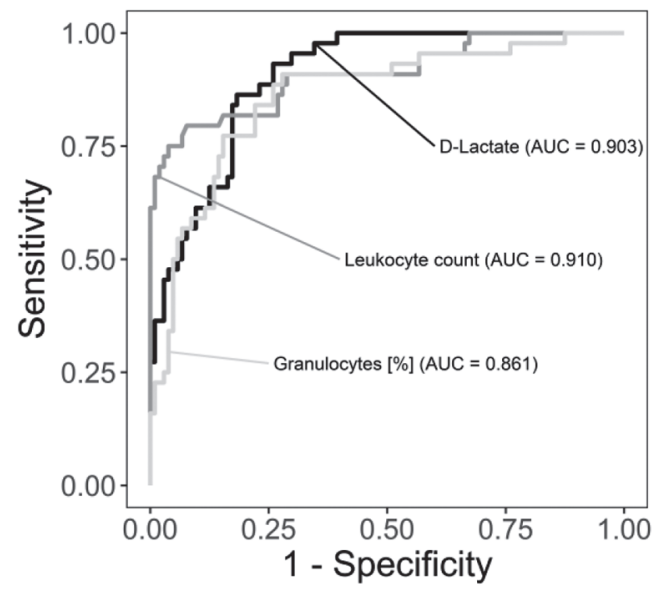

Fig. 2. The ROC curve of synovial fluid biomarkers for PJI. The AUC of D-lactate, leukocyte count and percentage of granulocytes are $0.903,0.910$ and 0.861 , respectively

\subsection{Alpha-defensin}

Of 212 included patients, 151 (71\%) had a knee prosthesis and 61 (29\%) had a hip prosthesis. PJI was diagnosed in 45 patients (21\%) using the MSIS criteria, in 55 patients $(26 \%)$ using the IDSA criteria and in 79 patients (37\%) using the proposed EBJIS criteria. The sensitivity of the ADLF test was $84 \%$ with the MSIS criteria, 67\% with the IDSA criteria, and $54 \%$ with the proposed EBIIS criteria. The ADLF test showed high specificity using all classification criteria (96\% to 99\%) and represented the most specific preoperative test for PJI, especially in the early postoperative period (91\%; 95\% CI, 59\% to 100\%). Using the proposed EBJIS definition criteria, the sensitivity of the leukocyte count was significantly higher than that of the ADLF test (86\% [95\% CI, 76\% to 93\%] compared with $54 \%$ [95\% CI, $43 \%$ to $66 \%$ ]; $p<0.001$ ), particularly in chronic PJI (81\% compared with $44 \%$, respectively; $p<0.001$ ) (Fig. 3).

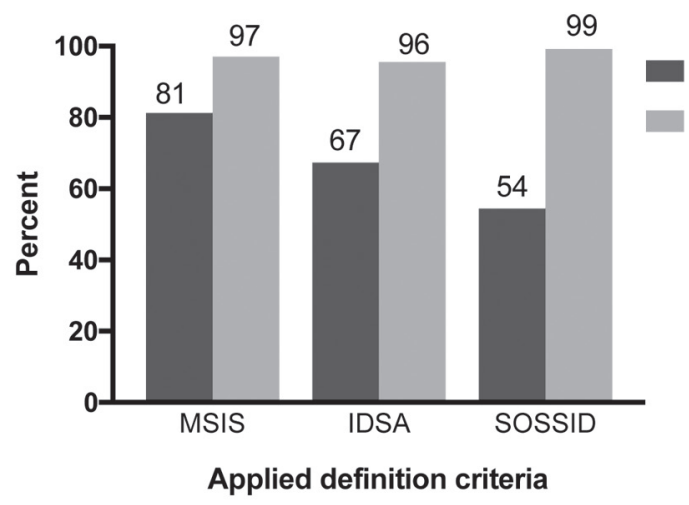

Sensitivity Specificity

\subsection{PCR of synovial fluid}

Synovial fluid leukocytes (absolute leukocyte count or percentage of granulocytes) was the most sensitive diagnostic criterion for the diagnosis of PJI (86\%). The sensitivity of synovial fluid PCR was 60\% and herewith comparable with synovial fluid culture $(52 \%, p=0.239)$ (Fig. 4).

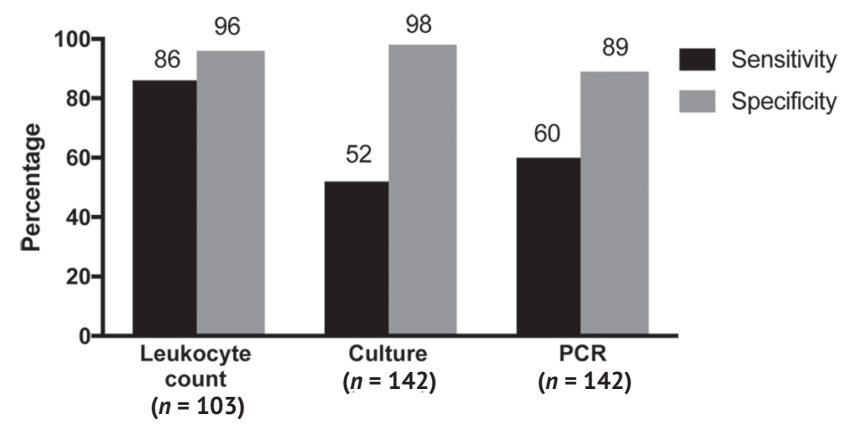

Fig. 4. Performance of intraoperative diagnostic tests

In 116 of 142 patients ( $82 \%$ ), synovial fluid culture and PCR showed concordant results, including $58 \mathrm{PJI}$ and 58 aseptic cases. In patients with PJI, PCR missed 6 where cultures grew the pathogen, including $S$. aureus (2 isolates), $S$. mitis/oralis (2 isolates), E. coli and E. faecalis (1 isolate each), most of them being classified as high-virulent microorganisms. For $S$. mitis/oralis, no primers are included in the PCR test kit and therefore, in 2 cases the causative pathogen was not detectable by this method. In contrast, synovial fluid cultures missed 13 pathogens.

\section{Intraoperative diagnostic tests}

\subsection{Sonication}

We studied 331 patients with total knee prostheses (207 patients) or hip prostheses (124 patients); 252 patients had aseptic failure, and 79 had prostheticjoint infection. With the use of standardized criteria to define PJI, the sensitivities of periprosthetic-tissue and sonicate-fluid cultures were $60.8 \%$ and $78.5 \%$ $(p<0.001)$, respectively, and the specificities were $99.2 \%$ and $98.8 \%$, respectively.

Fig. 3. The performance of the ADLF test according to the three classification systems for the diagnosis of PJI: the Musculoskeletal Infection Society (MSIS) criteria, the Infectious Diseases Society of America (IDSA) criteria, and the proposed European Bone and Joint Infection Society (EBJIS) criteria 


\subsection{PCR of sonication fluid}

Among 111 patients, PJI was diagnosed in 78 (70\%) and aseptic failure in 33 (30\%). For the diagnosis of PJI, the sensitivity and specificity of periprosthetic tissue culture was $51 \%$ and $100 \%$, of sonication fluid culture $58 \%$ and $100 \%$, and of sonication fluid PCR $51 \%$ and $94 \%$, respectively. Among 70 microorgan- isms, periprosthetic tissue culture grew 52 (74\%), sonication fluid culture grew $50(71 \%)$ and sonication fluid PCR detected 37 pathogens (53\%). If only organisms are considered, for which primers are included in the test panel, the PCR detected 37 of 58 pathogens (64\%). The sonication fluid PCR missed 19 isolates, but detected 7 additional microorganisms where cultures were negative (Table).

Performance of the microbiological tests for the diagnosis of PJI in 111 patients,

Table including 78 subjects with PJI and 33 with aseptic failures

\begin{tabular}{|l|c|c|c|c|c|c|}
\hline \multicolumn{1}{|c|}{ Microbiological test } & $\begin{array}{c}\mathrm{PJI} \\
(n=78)\end{array}$ & $\begin{array}{c}\mathrm{AF} \\
(n=33)\end{array}$ & $\begin{array}{c}\text { Sensitivity } \\
(\%)\end{array}$ & $\begin{array}{c}\text { Specificity } \\
(\%)\end{array}$ & $\begin{array}{c}\text { Positive } \\
\text { predictive } \\
\text { value (\%) }\end{array}$ & $\begin{array}{c}\text { Negative } \\
\text { predictive } \\
\text { value (\%) }\end{array}$ \\
\hline $\begin{array}{l}\text { Periprosthetic tissue culture } \\
\text { Sonication fluid culture }\end{array}$ & 40 & 0 & $51(40-63)$ & $100(89-100)$ & $100(91-100)$ & $46(35-59)$ \\
\hline $\begin{array}{l}\text { Sonication fluid PCR } \\
\text { (clinical performance) }\end{array}$ & 40 & 0 & $58(46-69)$ & $100(89-100)$ & $100(-)$ & $50(44-56)$ \\
\hline $\begin{array}{l}\text { Sonication fluid PCR } \\
\text { (analytical performance) }\end{array}$ & $40 / 75$ & 2 & $53(41-65)$ & $94(80-99)$ & $95(84-99)$ & $47(41-53)$ \\
\hline
\end{tabular}

\subsection{Chemical biofilm dislodgement methods}

In the sonication group, 102 patients (37 with PJI and 65 with aseptic failure (AF)) were included. Sonication had significantly higher sensitivity for the diagnosis of PJI as compared to tissue culture (80\% vs. $58 \%, p<0.01$ ) and showed comparable results in comparison with histopathology and SF leukocytes (89\% and $89 \%$, respectively, $p>0.05$ ) (Fig. 5 a).
In the DTT-based method, 93 patients were included (35 with PJI and 58 with AF). DTT-based method showed low sensitivity for diagnosis of PJI (40\%) compared to all other used diagnostic tests $(p<0.01)$ (Fig. 5 b). In 12 patients with culture positive PJI, MicroDTTect was false negative. In 4 patients with clinical sinces of infection but culture negative, MicroDTTect showed positive results.
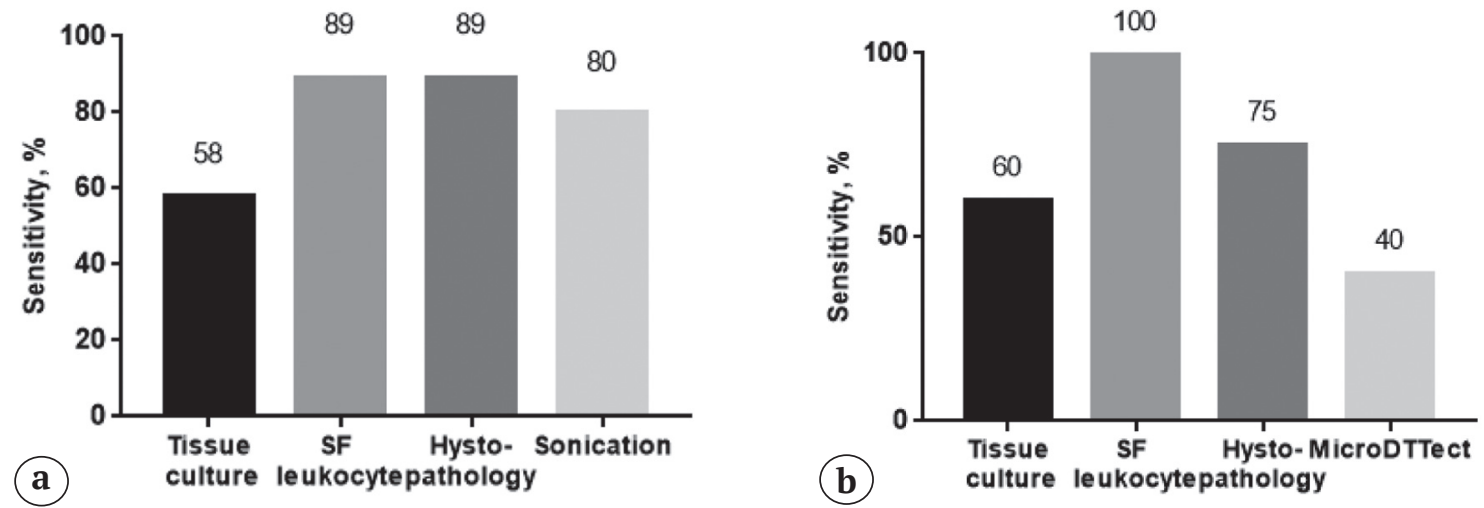

Fig. 5. Sensitivity of the tests in sonication group (a) and in MicroDTTect (b) 


\section{Discussion}

The synovial fluid D-lactate in our cohort showed better sensitivity than synovial fluid leukocyte count and percentage of granulocytes to diagnose septic arthritis and PJI. The concentration of D-lactate reflects the virulence of the bacterial species and its microbial burden, which explains the observed differences. Furthermore, it is important to recognize uncommon disorders which cause D-lactate acidosis and increase D-lactate in blood and body fluids, namely in the setting of short bowel syndrome. Concomitant severe, uncontrolled diabetes mellitus with insulin deficiency may also cause increased D-lactate levels in plasma and urine [14]. Further studies need to explore underlying conditions potentially influencing the D-lactate concentration, which may elucidate the limited specificity of the test.

To assess the performance of alpha defensin lateral flow (ADLF) test for the diagnosis of PJI three classification systems were used $[15,16,17,18,19$, $20]$. When the proposed EBJIS criteria were used, the ADLF test performed worse, especially for chronic infections. Whereas the MSIS and IDSA criteria may miss some patients with PJI (false negative), the proposed EBJIS criteria may be prone to misdiagnose patients who are aseptic as having PJI (false positive), leading to unnecessary surgical interventions and antimicrobial treatments. The leukocyte count in synovial fluid may be elevated (false positive) because of aseptic inflammatory pathologies, such as rheumatic joint disease, periprosthetic fracture, or dislocation, and in the early postoperative period. In these situations, the proposed EBJIS criteria require an additional confirmatory criterion to be fulfilled, as the leukocyte count is not applicable. The leukocyte count in synovial fluid can be falsely negative if a sinus tract is present, as the inflammatory fluid is drained. However, in the presence of a sinus tract, the diagnosis of PJI is confirmed and additional tests are not needed.

Among the evaluated microbiological tests, synovial fluid multiplex PCR showed a comparable sensitivity to synovial fluid culture (60\% vs. $52 \%)$. While the overall performance was similar, synovial fluid PCR was superior to culture for detection of low-virulent bacteria. In addition, culture of synovial fluid required several days for growth, whereas multiplex PCR provided results within 5 hours in an automated manner. However, the relevance of positive PCR results remains unknown and demonstrated the difficulty discriminating between false-positive from true-positive findings.

The results of our study show that sonication of removed orthopedic implants is more sensitive than tissue culture. Our results emphasize the importance of performing both aerobic and anaerobic sonicatefluid culture; $11 \%$ of positive cultures were obtained only on anaerobic plates and 5\% of positive cultures only on aerobic plates. Improved detection of polymicrobial prosthetic-joint infection appears to be another advantage of sonicate-fluid culture. The sensitivity of sonication fluid multiplex PCR in our study (51\%) was comparable with the sensitivity of periprosthetic tissue culture (51\%) and sonication fluid culture (58\%). Newer PCR systems were extended to include additional primers, to detect most commonly involved microorganisms in PJI [21, 22, 23, 24].

In our study, we investigated the ability of sonication and DTT-based method, MicroDTTect to dislodge biofilm from implant surface and therefor improve microbiological diagnosis of PJI. MicroDTTect showed low sensitivity for diagnosis of PJI (40\%) compared to all other used diagnostic tests $(p<0.01)$. Our results were discordant to those showed by Drago et al. [25]. They showed that DTT had better sensitivity (85.7\%) compared to sonication (71.4\%) for the diagnosis of PJI.

Several new preoperative and intraoperative diagnostic tests were recently evaluated. Among preoperative tests, synovial fluid D-lactate demonstrated good analytical performance and diagnostic value for the diagnosis of septic arthritis and PJI. In particular, the high sensitivity for diagnosing infection and rapid availability of the test result make synovial fluid D-lactate suitable as screening test, whereas ADLF had limited sensitivity (54\%) but high specificity (>95\%) and it should therefore not be used for screening, but rather as a confirmatory test for PJI. Multiplex PCR of synovial fluid has similar sensitivity and specificity to synovial fluid culture, having the advantage of rapid availability of results (within 5 hours) and fully automated process. With further improvement of its performance and inclusion of additional primers (e.g. for streptococci), multiplex PCR may complement conventional cultures, especially for rapid and accurate diagnosis of low-grade PJI. However, it cannot yet replace the culture technique due to low sensitivity and the need of reliable susceptibility testing.

Among intraoperative tests, culture of samples obtained by sonication of prostheses showed the best sensitivity for the microbiologic diagnosis of prosthetic hip and knee infection compared to conventional periprosthetic-tissue culture. Whwreras, the performance of sonication fluid PCR is comparable to periprosthetic tissue or sonication fluid cultures. The only advantage of PCR is short processing time (5 hours) and fully automated procedure. Chemical based dislodgement such as MicroDTTect has low analytical performance for the diagnosis of PJI and is less sensitive than 
sonication method. Further investigations need to evaluate the stability of microorganisms after adding DTT - a possible reason for lower performance of MicroDTTect and potential improvement of its performance.

\section{Publication ethics}

Competing interests: the authors declare that there are no competing interests.

Funding: no funding or sponsorship was received for this study or publication of this article.

\section{Authors' contribution}

S. Karbysheva, N. Renz, K. Yermak and S. Cabric collected, analysed and interpreted the data and drafted the manuscript. AT elaborated the study design and performed major revisions of the manuscript draft. All authors read and approved the final manuscript.

All authors meet criteria for authorship, have seen and approved the final version of the manuscript.

\section{References}

1. Kaandorp C.J., Dinant H.J., van de Laar M.A., Moens H.J., Prins A.P., Dijkmans B.A. Incidence and sources of native and prosthetic joint infection: a community based prospective survey. Ann Rheum Dis. 1997;56(8):470-475. doi: 10.1136/ard.56.8.470.

2. Portillo M.E., Salvadó M., Alier A., Sorli L., Martínez S., Horcajada J.P., Puig L. Prosthesis failure within 2 years of implantation is highly predictive of infection. Clin Orthop Relat Res. 2013;471(11):3672-3678. doi: 10.1007/s11999-013-3200-7.

3. Corvec S., Portillo M.E., Pasticci B.M., Borens O., Trampuz A. Epidemiology and new developments in the diagnosis of prosthetic joint infection. Int J Artif Organs. 2012;35(10):923-934. doi: 10.5301/ijao.5000168.

4. Winkler T., Trampuz A., Renz N., Perka C., Bozhkova S. [Classification and algorithm for diagnosis and treatment of hip prosthetic joint infection]. Travmatologiya $i$ ortopediya Rossii [Traumatology and Orthopedics of Russia]. 2016;(1):21-32. (In Russian).

5. Berbari E.F., Marculescu C., Sia I., Lahr B.D., Hanssen A.D., Steckelberg J.M. et al. Culture-negative prosthetic joint infection. Clin Infect Dis. 2007;45(9):1113-1119. doi: 10.1086/522184.

6. Abdullah S., Young-Min S.A., Hudson S.J., Kelly C.A., Heycock C.R., Hamilton J.D. Gross synovial fluid analysis in the differential diagnosis of joint effusion. J Clin Pathol. 2007;60(10):1144-1147.

7. Sharff K.A., Richards E.P., Townes J.M. Clinical management of septic arthritis. Curr Rheumatol Rep. 2013;15(6):332. doi: 10.1007/s11926-013-0332-4.

8. Karbysheva S.B., Grigoricheva L.G., Zhyltsov I.V., Semenov V.M., Zolovkina A.G., Veremei I.S., Trampuz A. [Synovial Fluid D-lactate - Bacterial-Specific Marker for Infection of Native and Prosthetic Joints]. Travmatologiya $i$ ortopediya Rossii [Traumatology and Orthopedics of Russia]. 2017;23(2):6-14. (In Russian). doi: 10.21823/2311-2905-2017-23-2-6-14.

9. Gratacos J., Vila J., Moya F., Marcos M.A., Collado A., Sanmarti R. et al. D-lactic acid in synovial fluid. A rapid diagnostic test for bacterial synovitis. J Rheumatol. 1995;22:1504-1508.

10. Yermak K., Karbysheva S., Perka C., Trampuz A., Renz N. Performance of synovial fluid D-lactate for the diagnosis of periprosthetic joint infection: A prospective observational study. J Infect. 2019;79(2):123-129. doi: 10.1016/j.jinf.2019.05.015.

11. Holinka J., Bauer L., Hirschl A.M., Graninger W., Windhager R., Presterl E. Sonication cultures of explanted components as an add-on test to routinely conducted microbiological diagnostics improve pathogen detection. J Orthop Res. 2011;29(4):617-622. doi: 10.1002/jor.21286.

13. Zimmerli W., Trampuz A. Implant-Associated Infection. In: Bjarnsholt T., Jensen P.Ø., Moser C., Høiby N., ed. Biofilm Infections. NY: Springer New York; 2011:69-90.

13. Kobayashi H., Oethinger M., Tuohy M.J., Procop G.W., Bauer T.W. Improved detection of biofilm-formative bacteria by vortexing and sonication: a pilot study. Clin Orthop Relat Res. 2009;467(5):1360-1364. doi: 10.1007/s11999-008-0609-5.

14. Scheijen J.L., Hanssen N.M., van de Waarenburg M.P., Jonkers D.M., Stehouwer C.D., Schalkwijk C.G. L(+) and $\mathrm{D}(-)$ lactate are increased in plasma and urine samples of type 2 diabetes as measured by a simultaneous quantification of $\mathrm{L}(+)$ and $\mathrm{D}(-)$ lactate by reversed-phase liquid chromatography tandem mass spectrometry. Exp Diabetes Res. 2012;2012:234812. doi: 10.1155/2012/234812.

15. Kasparek M.F., Kasparek M., Boettner F., Faschingbauer M., Hahne J., Dominkus M. Intraoperative Diagnosis of Periprosthetic Joint Infection Using a Novel Alpha-Defensin Lateral Flow Assay. J Arthroplasty. 2016;31(12):2871-2874. doi: 10.1016/j.arth.2016.05.033.

16. Parvizi J., Gehrke T.; International Consensus Group on Periprosthetic Joint Infection. Definition of periprosthetic joint infection. J Arthroplasty. 2014;29(7):1331. doi: 10.1016/j.arth.2014.03.009.

17. Parvizi J., Gehrke T., Chen A.F. Proceedings of the International Consensus on Periprosthetic Joint Infection. Bone Joint J. 2013;95-B(11):1450-1452. doi: 10.1302/0301-620X.95B11.33135.

18. Parvizi J., Tan T.L., Goswami K., Higuera C., Della Valle C., ChenA.F., Shohat N.The 2018Definition of Periprosthetic Hip and Knee Infection: An Evidence-Based and Validated Criteria. J Arthroplasty. 2018;33(5):1309-1314.e2. doi: 10.1016/j.arth.2018.02.078.

19. Parvizi J., Zmistowski B., Berbari E.F., Bauer T.W., Springer B.D., Della Valle C.J. et al. New definition for periprosthetic joint infection: from the Workgroup of the Musculoskeletal Infection Society. Clin Orthop Relat Res. 2011;469(11):2992-2994. doi: 10.1007/s11999-011-2102-9.

20. Sigmund I.K., Holinka J., Gamper J., Staats K., Böhler C., Kubista B., Windhager R. Qualitative $\alpha$-defensin test (Synovasure) for the diagnosis of periprosthetic infection in revision total joint arthroplasty. Bone Joint J. 2017;99-B(1):66-72. doi: 10.1302/0301-620X.99B1.BJJ-2016-0295.R1.

21. Hall-Stoodley L., Costerton J.W., Stoodley P. Bacterial biofilms: from the natural environment to infectious diseases. Nat Rev Microbiol. 2004;2(2):95-108. doi: $10.1038 /$ nrmicro821.

22. Portillo M.E., Salvadó M., Alier A., Martínez S., Sorli L., Horcajada J.P., Puig L. Advantages of sonication fluid culture for the diagnosis of prosthetic joint infection. $J$ Infect. 2014;69(1):35-41. doi: 10.1016/j.jinf.2014.03.002. 
23. Portillo M.E., Salvadó M., Trampuz A., Siverio A., Alier A., Sorli L. et al. Improved diagnosis of orthopedic implant-associated infection by inoculation of sonication fluid into blood culture bottles. J Clin Microbiol. 2015;53(5):1622-1627. doi: 10.1128/JCM.03683-14.
24. Tande A.J.,Patel R.Prosthetic joint infection.Clin Microbiol Rev. 2014;27:302-345. doi: 10.1128/CMR.00111-13.

25. Drago L., Signori V., De Vecchi E., Vassena C., Palazzi E., Cappelletti L. et al. Use of dithiothreitol to improve the diagnosis of prosthetic joint infections. J Orthop Res. 2013;31(11):1694-1699. doi: 10.1002/jor.22423.

AUTHORS' AFFILATIONS:

Svetlana Karbysheva - Clinical Microbiologist, Center for Septic Surgery, Charité - University Medicine Berlin, Berlin, Germany

Nora Renz - Infection Disease Specialist, Center for Septic Surgery, Charité - University Medicine Berlin, Berlin, Germany Katsiaryna Yermak - Research Fellow, Center for Septic Surgery, Charité - University Medicine Berlin, Berlin, Germany

Sabrina Cabric - Research Fellow, Center for Septic Surgery, Charité - University Medicine Berlin, Berlin, Germany

Trampuz Andrej - Head of the Center for Septic Surgery, Charité - University Medicine Berlin; Research Group Leader of the Biofilm Research Laboratory, Berlin, Germany 